\title{
INTERSYSTEM EXTRAPOLATION FACTORS (ISEF) ARE SUBSTRATE-DEPENDENT FOR CYP3A4: IMPACT ON CYTOCHROME P450 REACTION PHENOTYPING
}

\author{
Alyssa L. Dantonio, Angela C. Doran, and R. Scott Obach \\ Pfizer Inc. \\ Groton, CT, USA 06340
}


Running Title: ISEF for Cytochrome P4503A4

Corresponding Author: R. Scott Obach, Pfizer Inc., Eastern Point Rd, Groton, CT, 06340

r.scott.obach@pfizer.com

Number of:

Text Pages: 18

Tables: 5

Figures: 5

References: 43

Words in Abstract: 240

Words in Introduction: 760

Words in Discussion: 1061

Abbreviations: DDI, drug-drug interactions; $\mathrm{f}_{\mathrm{m}}$, fraction metabolized; ISEF, intersystem extrapolation

factor; $f_{u, \text { mic }}$ unbound fraction in microsomes; NADPH, nicotinamide adenine nucleotide diphosphate-

reduced form; RAF, relative activity factor; RAbF, relative abundance factor; rCYP, heterologously

expressed individual P450 enzymes 


\section{ABSTRACT}

The use of intersystem extrapolation factors (ISEF) is required for the quantitative scaling of drug metabolism data generated in individually expressed cytochrome P450 enzymes when estimating fractional contribution to metabolism by P450 enzymes in vivo $\left(f_{m}, c Y p\right)$. For successful prediction of $f_{m}$, ISEF values must be universal across all substrates for any individual enzyme. In this study, ISEF values were generated for ten CYP3A4 selective substrates using a common source of recombinant heterologously expressed CYP3A4 and a pool of human liver microsomes. The resulting ISEF values for CYP3A4 were substrate-dependent and ranged 8-fold, with the highest value generated from intrinsic clearance of midazolam depletion (0.36) and the lowest from quinidine depletion (0.044). Application of these ISEF values for estimation of the fractional contribution of CYP3A4 and CYP2C19 to omeprazole clearance yielded values that ranged from $0.21-0.63$ and $0.37-0.79$, respectively, as compared to backextrapolated in vivo $f_{m}$ values of 0.27 (CYP3A4) and 0.85 (CYP2C19) from clinical pharmacokinetic data. For risperidone, estimated $\mathrm{f}_{\mathrm{m}}$ values for CYP3A4 and CYP2D6 ranged from 0.87-0.98 and 0.02-0.13, respectively, as compared to in vivo values of 0.36 (CYP3A4) and $0.63-0.88$ (CYP2D6), showing that the importance of CYP3A4 was over-estimated and the importance of CYP2D6 under-estimated. Overall, these findings suggest that ISEF values for CYP3A4 can vary with the marker substrate used to derive them, thereby reducing the effectiveness of the approach of using metabolism data from rCYP3A4 with ISEF values for the prediction of $\mathrm{f}_{\mathrm{m}}$ values in vivo.

\section{SIGNIFICANCE STATEMENT}

Intersystem extrapolation factors (ISEF) are utilized for assigning fractional contributions of individual enzymes to drug clearance $\left(f_{m}\right)$ from drug metabolism data generated in recombinant P450s. The present data shows that ISEF values for cytochrome P4503A4 vary with the substrate. This can lead to variable and erroneous prediction of $f_{m}$. 


\section{INTRODUCTION}

Interindividual variability in drug pharmacokinetics can arise via a variety of mechanisms among which are differences in activities of drug metabolizing enzymes. Such differences can be caused by environmental factors such as drug-drug interactions (DDI) or effects of diet or dietary supplements on drug metabolizing enzyme activities. They can also arise from inherent differences in expression of drug metabolizing enzymes among individuals based on genetic variation. An understanding of the mechanistic underpinnings of interindividual differences in the pharmacokinetics of any given drug first requires the identification of enzymes involved in the metabolism of the drug followed by quantifying the relative contribution of each enzyme.

Among the drug metabolizing enzyme families, cytochrome P450 has the greatest involvement in drug clearance (Yu et al., 2014; Cerny, 2016; Guengerich, 2008). Hundreds of DDIs can be attributed to alterations of P450 activities, and pharmacogenetic differences in drug pharmacokinetics can be attributed to several of these enzymes. In vitro methods and reagents have been developed that enable the conduct of studies with the aim of assigning specific P450 enzymes in the metabolism of a drug; also termed "reaction phenotyping." (Rodrigues, 1999; Zhang et al., 2007; Lu et al., 2003; Zientek et al., 2015). These include human liver microsomes from individual donors that have been characterized for drug metabolism activities, compounds and antibodies which preferentially inhibit single P450 enzymes, and heterologously expressed individual P450 enzymes (rCYP) derived from recombinant DNA technology. Collectively, these reagents are used to develop knowledge of the P450 enzymes contributing to metabolism of a drug and the quantitative fraction of total metabolism each enzyme contributes, termed $f_{m}$ (fraction metabolized). 
The application of rCYP enzymes for quantitative reaction phenotyping has increased over time because of the ability to study isozyme activity in isolation from other contributing enzymes and an ability to employ higher enzyme concentrations affording enhanced sensitivity for detecting metabolism of low clearance compounds. When using rCYPs to quantitate $f_{m}$ for distinct P450 isoforms, the data must be appropriately scaled to represent the expression levels and activities of the respective enzymes in the liver. This led to the concepts of relative activity factors (RAFs) and relative abundance factors (RAbFs) wherein rate data for a drug metabolism reaction in an incubation with rCYP would be corrected by factors to account for natural differences in these enzymes' activities and expression levels, respectively. These concepts were further evolved to the intersystem extrapolation factor (ISEF; Chen, et al., 2011) that essentially combines RAFs and RAbFs to account for individual P450 enzymes having differences in specific activity between heterologous expression systems and human liver microsomes. The requirement for these scaling factors is determined by factors such as modulation of P450 activity by accessory proteins such as NADPH:P450 oxidoreductase and cytochrome $b_{5}$ that have different relative expression levels in heterologous systems vs liver microsomes, as well as demonstrated effects of one P450 enzyme on the activity of another when present together in a natural system (Reed and Backes, 2012).

However, a cornerstone of developing and using ISEFs is that the reactions used to define them are highly selective for the P450 enzyme of interest such that when evaluated in a mixture of enzymes (i.e. liver microsomes) the entire measured activity can be attributed to that one enzyme. Over the course of years, such reactions have been identified and carefully characterized. Additionally, it must also be assumed that the ISEF is constant for every substrate for a given P450 enzyme. However, this assumption may not always hold true: it has been shown that for CYP3A4 there are different substrate properties wherein the same inhibitor can have different potencies to different substrates, which has 
been attributed to multiple binding sites on the CYP3A4 enzyme (Kapelyukh, et al., 2008; Ekroos and Sjogren, 2006). Thus, ISEF values generated using one substrate may not be appropriate for another substrate, even when these are metabolized by the same P450 enzyme. This represents an important shortcoming for the application of ISEF, RAF, or RAbF approaches in estimating $f_{m}$ values as it would not be known, a priori, which marker substrate activity is most relevant for a metabolic reaction for a newly investigated drug.

The objective of the experiments reported herein is to determine the variation in ISEFs calculated for ten CYP3A4 substrates. This includes the use of midazolam, the most commonly employed CYP3A4 substrate, as a comparator. The substrates span a range of chemical structures and may bind to CYP3A4 in different fashions. The implications of the findings for the approach of scaling rate data from expressed P450 enzymes to predict $f_{m}$ values are discussed. 


\section{MATERIALS AND METHODS}

Materials. Substrates, metabolite standards, internal standard (IS), and inhibitors were obtained from the following sources: amlodipine, vardenafil, vincristine, and sildenafil from Sequoia Research Products, Pangbourne, UK; nisoldipine, triazolam, midazolam, eletriptan, felodipine, lidocaine, omeprazole, quinidine, risperidone, ketoconazole, CYP3cide, itraconazole, NADPH, and diclofenac (internal standard) from Sigma-Aldrich, St. Louis, MO; PF-05218881 and $\left[{ }^{2} \mathrm{H}_{4}\right] 1$ '-hydroxymidazolam (IS) were prepared at Pfizer (Groton, CT). Pooled HLM (lot HLM-102) prepared from 50 donors of mixed sex were obtained from BD Biosciences (Woburn, MA). Recombinant heterologously expressed CYP3A4 (rCYP3A4; 87 pmol CYP per mg protein) containing rabbit P450 oxidoreductase was prepared under contract by Panvera Corp. (Madison, WI).

Intrinsic Clearance Measurement in Pooled Human Liver Microsomes and Recombinant CYP3A4. Ten CYP3A selective substrates $(1.0 \mu \mathrm{M})$ were selected for incubation with rCYP3A4 and HLM-102 for ISEF determination based on substrate depletion. The rCYP and HLM protein concentrations selected for each incubation were based on the degree of substrate lability. The substrates amlodipine, eletriptan, quinidine, triazolam, and vincristine were incubated with rCYP3A4 at $100 \mathrm{pmol} / \mathrm{mL}$ and microsomal protein at $1 \mathrm{mg} / \mathrm{mL}$; midazolam, sildenafil and vardenafil with rCYP3A4 at $10 \mathrm{pmol} / \mathrm{mL}$ and microsomal protein at $0.1 \mathrm{mg} / \mathrm{mL}$; and felodipine and nisoldipine incubated with rCYP3A4 $1 \mathrm{pmol} / \mathrm{mL}$ and microsomal protein at $0.01 \mathrm{mg} / \mathrm{mL}$. All incubations were conducted in $100 \mathrm{mM} \mathrm{KH}_{2} \mathrm{PO}_{4}(\mathrm{pH} 7.4)$ containing $\mathrm{MgCl}_{2}(3.3-5.0 \mathrm{mM}$ for rCYP3A4 and HLM, respectively) and NADPH (1.2 mM) in a total volume of $0.5 \mathrm{~mL}$. Incubations were commenced with the addition of NADPH and carried out in a 96well heat block at a temperature of $37^{\circ} \mathrm{C}$. At times ranging between 0 and 60 minutes, aliquots $(0.05 \mathrm{~mL})$ were quenched with $0.2 \mathrm{~mL}$ of $100 \% \mathrm{CH}_{3} \mathrm{CN}$ containing IS (100 ng/mL PF-05218881). Terminated incubation mixtures were centrifuged at 2,300 x $\mathrm{g}$ for 5 min and supernatants $(0.15 \mathrm{~mL})$ dried under 
warm nitrogen stream. Residues were reconstituted in $10 / 90 \mathrm{CH}_{3} \mathrm{CN} /$ water containing $0.2 \%$ formic acid $(0.3 \mathrm{~mL})$. Samples were analyzed using a liquid chromatography-tandem mass spectrometry (LCMS/MS) system as described in Supplemental Tables 1 and 2. Experiments were conducted on at least two separate days each with replicates of $\mathrm{N}=2$. The duplicate intrinsic clearance $\left(\mathrm{CL}_{\text {int,app }}\right)$ determinations were measured within experiments and then averaged across different experimental days, followed by correction for free fraction in the incubation.

Substrate Saturation Experiments. Midazolam $(0.1-30 \mu \mathrm{M})$ was incubated with HLM $(0.01 \mathrm{mg} / \mathrm{mL})$ or rCYP3A4 (1 pmol/mL) in $100 \mathrm{mM} \mathrm{KH}{ }_{2} \mathrm{PO}_{4}(\mathrm{pH} 7.4)$ containing $\mathrm{MgCl}_{2}(3.3 \mathrm{mM})$, and $\mathrm{NADPH}(1.2 \mathrm{mM})$ in a total volume of $0.2 \mathrm{~mL}$. Reactions were initiated with the addition of substrate and conducted in a 96well heat block at a temperature of $37^{\circ} \mathrm{C}$. After $4 \mathrm{~min}$, aliquots $(0.05 \mathrm{~mL})$ were quenched with $0.2 \mathrm{~mL}$ of $100 \% \mathrm{CH}_{3} \mathrm{CN}$ containing internal standard $\left(20 \mathrm{ng} / \mathrm{mL}\left[{ }^{2} \mathrm{H}_{4}\right] 1\right.$ '-hydroxymidazolam), followed by centrifugation at $1440 \mathrm{xg}$ for $10 \mathrm{~min}$. Supernatants were dried under a warm nitrogen stream and residues were reconstituted in $75 / 25 \mathrm{CH}_{3} \mathrm{CN} / \mathrm{H}_{2} \mathrm{O}$ containing $0.1 \%$ formic acid $(0.2 \mathrm{~mL})$. Prepared samples were analyzed for 1'-hydroxymidazolam formation by LC-MS as described in Supplemental Tables 1 and 2. Two separate experiments were conducted on separate days each with replicates of $\mathrm{N}=3$. ISEF values were calculated within each experimental day, and then averaged across days for a final value.

Chemical Inhibition of CYP3A in HLM-102. Substrates $(1.0 \mu \mathrm{M})$ were incubated with HLM-102 at protein concentrations described above. Incubations were carried out in $100 \mathrm{mM} \mathrm{KH}_{2} \mathrm{PO}_{4}(\mathrm{pH}$ 7.4) containing $\mathrm{MgCl}_{2}(3.3 \mathrm{mM}), \mathrm{NADPH}(1.2 \mathrm{mM})$, and either ketoconazole $(1 \mu \mathrm{M})$ or CYP3cide $(1 \mu \mathrm{M})$ in a total volume of $0.5 \mathrm{~mL}$. Incubations were commenced with the addition of NADPH (for incubations with ketoconazole), or with the addition of substrate (for incubations with CYP3cide) and carried out in a 96- 
well heat block at a temperature of $37^{\circ} \mathrm{C}$. At times ranging between 0 and 60 minutes, aliquots $(0.05 \mathrm{~mL})$ were quenched with $0.2 \mathrm{~mL}$ of $100 \% \mathrm{CH}_{3} \mathrm{CN}$ containing IS (100 ng/mL PF-05218881). Terminated incubation mixtures were centrifuged at 2,300 x g for 10 min and supernatants $(0.1 \mathrm{~mL})$ were dried under warm nitrogen stream. Residues were reconstituted in $10 / 90 \mathrm{CH}_{3} \mathrm{CN} /$ water $(0.2 \mathrm{~mL})$ and analyzed by LC-MS/MS as described in Supplemental Tables 1 and 2. Additionally, standards of each of the analytes were co-injected with the inhibitors on the same HPLC-MS system to rule out the potential for interference of analyte response by ion suppression.

Estimation of CYP3A4 $\mathrm{f}_{\mathrm{m}}$ for Risperidone and Omeprazole. Risperidone $(1 \mu \mathrm{M})$ was incubated with HLM$102(1 \mathrm{mg} / \mathrm{mL}), \mathrm{rCYP} 3 A 4(100 \mathrm{pmol} / \mathrm{mL})$, and rCYP2D6 (10 pmol/mL), and omeprazole $(0.25 \mu \mathrm{M})$ was incubated with HLM-102 (1 mg/mL), rCYP3A4 (10 pmol/mL), and rCYP2C19 (10 pmol/mL). Incubations were carried out in $100 \mathrm{mM}$ (pH 7.4) containing $\mathrm{MgCl}_{2}$ (3.3 or $5 \mathrm{mM}$ ) and NADPH (1.2 mM). Incubations were commenced with the addition of substrate and carried out in a 96-well heat block at a temperature of $37^{\circ} \mathrm{C}$. At times ranging between 0 and 60 minutes, aliquots $(0.04 \mathrm{~mL})$ were quenched with $0.16 \mathrm{~mL}$ of $100 \% \mathrm{CH}_{3} \mathrm{CN}$ containing internal standard $(25 \mathrm{ng} / \mathrm{mL}$ diclofenac). Terminated incubation mixtures were centrifuged at 2,300 $\mathrm{x}$ f for $5 \mathrm{~min}$ and supernatants diluted with $0.1 \%$ formic acid in water (risperidone, 1:1 v/v) or $250 \mathrm{mM}$ ammonium acetate in water (omeprazole, 1:1 v/v) to prevent chemical degradation. LC-MS/MS method details for each substrate are included in Supplemental Tables 1 and 2. A single experiment was conducted with replicates of $\mathrm{N}=3$.

Data Analysis. LC-MS/MS chromatograms were quantified using area ratios (analyte peak area/internal standard peak area) using AB Sciex Analyst software (versions 1.4 -1.7). The natural logarithm of percent remaining data were plotted against time and slopes determined using a linear regression model in GraphPad Prism (versions 6 - 9). Data point selection to establish linearity was assessed in 
GraphPad using comparison of best fit model by sequential elimination of the latter time points until the preferred fitting was to a linear model. Data points that represented $<15 \%$ of substrate remaining were also generally excluded.

For ISEF determination by enzyme kinetic analysis, 1'-hydroxymidazolam concentrations were quantified against a standard curve with an applied weighting of $1 / x^{2}$ using $A B$ Sciex Analyst software (version 1.7). The coefficient of determination, $r^{2}$, was greater than 0.99 for the calibration curves.

Unbound intrinsic clearance using substrate depletion (and binding values listed in Supplemental Table 3) was determined for the various substrates using the following equation:

Equation 1:

$$
C L_{\text {int }, u}=\frac{0.693}{t_{1 / 2}} \times \frac{m L \text { incubation }}{m g \text { microsomal protein or pmol CYP enzyme }} \times \frac{1}{f_{u, m i c}}
$$

Since $f_{u, m i c}$ was not measured at the same protein concentrations used in the intrinsic clearance determination experiments, the following equation was used to adjust the $f_{u, m i c}$ :

Equation 2:

$$
f_{u, 2}=\frac{1}{\frac{C_{2}}{C_{1}}\left(\frac{1-f_{u, 1}}{f_{u, 1}}\right)+1}
$$

where $C_{1}$ is protein concentration used in measured value, $f_{u, 1}$ is the measured $f_{u, \text { mic }}$ value, $C_{2}$ is the protein concentration used in calculated value, and $f_{u, 2}$ is the calculated fumic value (Austin, et al., 2002). Measured $f_{u, 1}$ values were either determined in-house or obtained from literature.

Drug-specific $\mathrm{CL}_{\text {int }}$ ISEFs from substrate depletion analysis were calculated for the various substrates using the following equation (Chen, et al., 2011):

Equation 3:

$$
\text { CLint ISEF }=\frac{C L i n t, u(H L M)}{C L i n t, u(r C Y P) \times C Y P 3 A 4 \text { abundance }(H L M)}
$$


In which the value used for CYP3A4 abundance in HLM is $137 \mathrm{pmol} / \mathrm{mg}$. Kinetic constants for midazolam

1-hydroxylase activity were determined from substrate saturation experiments in HLM and rCYP3A4

based on curve fitting to either the Michaelis-Menten (Equation 4) or Substrate Inhibition model

(Equation 5), respectively, using GraphPad 6 for Windows:

Equation 4:

$$
Y=\frac{V_{\max } \times X}{K_{M}+X}
$$

Equation 5:

$$
Y=\frac{V_{\max } \times X}{\left(K_{M}+X \times\left(1+X / K_{i}\right)\right.}
$$

where $\mathrm{X}$ is substrate concentration, $\mathrm{Y}$ is enzyme activity, $\mathrm{V}_{\max }$ is maximum enzyme activity, $\mathrm{K}_{\mathrm{M}}$ is Michaelis-Menten constant for enzyme activity, and $\mathrm{K}_{\mathrm{i}}$ represents substrate inhibition at high concentrations. Intrinsic clearance $\left(\mathrm{CL}_{\text {int,app }}\right)$ was as calculated from the enzyme kinetic parameters as $\mathrm{V}_{\mathrm{max}} / \mathrm{K}_{\mathrm{M}}$ and corrected for free fraction in microsomal incubations.

The ISEF derived from enzyme kinetics parameters of 1'-hydroxymidazolam metabolite formation was calculated using the following equation (Chen, et al., 2011):

Equation 6:

$$
\text { Kinetics ISEF }=\frac{V_{\max } / K_{M}(H L M)}{V_{\max } / K_{M}(r h C Y P) \times C Y P 3 A 4 \text { abundance }(H L M)}
$$

Contribution by CYP3A4 from chemical inhibition studies was calculated using the following equations:

Equation 7:

$$
\% \text { CYP3A Contribution }=\frac{\text { CLint }_{\text {control }}-\text { CLint }_{I N H}}{\text { CLint }_{\text {control }}}
$$

where $\mathrm{CL}_{\text {int,INH }}$ is the intrinsic clearance in the presence of inhibitor (ketoconazole or CYP3cide). 
CYP3A4, CYP2C19, and CYP2D6 abundance values in HLM were obtained from SimCYP Population-based Simulator Version 19 (SimCYP LTD, Sheffield, UK). Physiological scaling factors of $45 \mathrm{mg}$ microsomal protein per gram liver and $20 \mathrm{~g}$ liver per kg body weight, in addition to applying ISEF and CYP abundance scaling, were used to scale intrinsic clearance between $\mathrm{CL}_{\text {int, }, u}$ and $\mathrm{CL}_{\text {int,sc,u }}$ (units of $\mathrm{mL} / \mathrm{min} / \mathrm{kg}$ ) (Houston, 1994).

The $f_{m}$ values for risperidone and omeprazole were calculated using the following equation:

Equation 9:

$$
f_{m}=\frac{C L_{\text {int }, a p p, s c, u C Y P_{x}}}{C L_{\text {int }, a p p, s c, u C Y P_{\text {total }}}}
$$

Where $\mathrm{CYP}_{\mathrm{x}}$ represents the ISEF-scaled value from a single CYP isoform, and $\mathrm{CYP}_{\text {total }}$ represents the sum of scaled values from all CYP isoforms. 


\section{RESULTS}

Ten drugs were selected for this evaluation. These included well-established and highly utilized CYP3A substrates such as midazolam, triazolam, and felodipine. These are also well-established as CYP3A4 cleared drugs through demonstration of DDI with well-known potent CYP3A inhibitors such as ketoconazole, itraconazole, and ritonavir (Table 1).

Enzyme Kinetics of Midazolam 1'-Hydroxylation and Derivation of ISEF by Metabolite Formation. The enzyme kinetic parameters and intrinsic clearance values describing the formation of $1^{\prime}$ hydroxymidazolam in human liver microsomes and rCYP3A4 are presented in Table 2, and substrate saturation plots are depicted in Figure 1. A Michaelis-Menten or substrate inhibition model was used to estimate the kinetic parameters for midazolam 1'-hydroxylase in HLMs from two separate experiments. Values for $\mathrm{K}_{\mathrm{M}}$ were 1.62 and $1.37 \mu \mathrm{M}$, for $\mathrm{V}_{\max }$ were 852 and $646 \mathrm{pmol} / \mathrm{min} / \mathrm{mg}$, and for $\mathrm{CL}_{\text {int, }, \mathrm{u}}$ were 525 and $472 \mathrm{~mL} / \mathrm{min} / \mathrm{mg}$ (based on the midazolam $\mathrm{f}_{\mathrm{u} \text {,mic }}$ of 1 ). In rCYP3A4, a substrate inhibition model best described the kinetics with estimated parameters of 0.412 and $0.448 \mu \mathrm{M}$ for $\mathrm{K}_{\mathrm{M}}, 6.73$ and 5.35 $\mathrm{pmol} / \mathrm{min} / \mathrm{pmol}$ for $\mathrm{V}_{\max }$, and 16.3 and $11.9 \mathrm{~mL} / \mathrm{min} / \mathrm{pmol}$ for $\mathrm{CL}_{\text {int, } \mathrm{u}}$ for the two respective experiments. Using a CYP3A4 abundance value of $137 \mathrm{pmol} / \mathrm{mg}$ microsomal protein from SimCYP (version 19), ISEF values of 0.23 and 0.29 were calculated for the two separate experiments with an arithmetic mean of 0.26 .

Intrinsic Clearance of Ten CYP3A Substrates and Estimation of ISEF Values by Substrate Depletion. Substrate depletion rates were measured for ten CYP3A substrates $(1 \mu \mathrm{M})$ in HLM and rCYP3A4, shown in Figure 2 and listed in Table 3. Intrinsic clearance values in human liver microsomes ranged from 12.8 (vincristine) to 7093 (nisoldipine) $\mu \mathrm{L} / \mathrm{min} / \mathrm{mg}$ microsomal protein. The rates correlated between HLM and rCYP3A4 $\left(r^{2}=0.869\right)$ albeit the rank order was not exact. ISEF values were calculated for each and 
ranged from 0.044 for quinidine to 0.36 for midazolam (at a substrate concentration $1 \mu \mathrm{M}$ ). There appeared to be three clusters of ISEF values: high values of 0.26 to 0.36 (midazolam, nisoldipine, vardenafil, and midazolam 1'-hydroxylase from above), to moderate values of 0.14 to 0.19 (triazolam, sildenafil, felodipine, and vincristine), and low values of 0.044 to 0.077 (quinidine, eletriptan, and amlodipine). A second study using a reduced substrate concentration ( $0.1 \mu \mathrm{M})$ was conducted to ensure sub-saturating incubation conditions (below $K_{M}$ ) for compounds known to have low $K_{M}$ values in the dataset. Assessed in the follow up experiment, the recalculated ISEFs for midazolam, quinidine, and nisoldipine following the reduction in substrate concentration were $0.15,0.044$, and 0.14 , respectively. A summary of the resulting range in ISEF values is depicted in Figure 3.

Verification of the Role of CYP3A in Metabolism of the Test Substrates. When using the overall substrate consumption to estimate ISEF values, it is critical that CYP3A4 is exclusively involved in the metabolism in HLM. If other enzymes were to meaningfully contribute, the resulting ISEF values would be erroneous. To establish this, the intrinsic clearance of these substrates was evaluated in HLM in the presence and absence of ketoconazole (CYP3A4/5 inhibitor) and cyp3cide (CYP3A4 selective inactivator), shown in Figure 4. For eight of ten compounds, ketoconazole caused marked inhibition such that depletion rates in the inhibited state could not be reliably measured. Felodipine consumption was inhibited $80 \%$ by ketoconazole, suggesting that the ISEF value of 0.17 derived from this drug should be lowered by $20 \%$. Amlodipine depletion was too slow in the control experiment to estimate the extent of inhibition by ketoconazole. Instead, an evaluation was made of dehydroamlodipine formation in human hepatocytes pretreated with the CYP3A inactivator troleandomycin $(25 \mu \mathrm{M})$ by monitoring the dehydroamlodipine peak in the HPLC-UV trace. (Dehydroamlodipine is the only metabolite of amlodipine generated by CYP3A4 (Zhu, et al. 2014)). The results indicated $97 \%$ inhibition of metabolite formation, supporting that amlodipine is almost entirely metabolized by CYP3A. As expected, based on 
the low CYP3A5 expression in the lot of HLM used, the resulting CYP3A4 inhibition by cyp3cide was similar, if not identical, to inhibition by ketoconazole. Overall, these findings support the use of these ten drugs for estimation of CYP3A4 ISEF values.

Case Examples: Estimation of CYP3A4 $\mathrm{f}_{\mathrm{m}}$ for Risperidone and Omeprazole. ISEF values are used in P450 reaction phenotyping for scaling of data gathered in individually expressed P450 enzymes. When CYP3A4 is a contributor to the metabolism of a drug, but not the sole contributor, the accuracy of the ISEF value used can have an influence on the resulting $f_{m}$ values for all enzymes involved. The exercise of applying ISEFs to estimating $\mathrm{f}_{\mathrm{m}}$ values was applied to predictions for risperidone and omeprazole (Figure 5). The drugs were selected for having CYP3A4/5 and one additional isoform as the two primary contributing enzymes. Risperidone is metabolized by CYP3A4 and CYP2D6 (Yasui-Furukori, et al., 2001) while omeprazole is metabolized by CYP3A4 and CYP2C19 (Yamazaki, et al., 1997; Abelo, et al., 2000). The estimated $f_{m}$ values for risperidone were calculated using a range of ISEF values, that were derived from the enzyme kinetics of midazolam 1'-hydroxylase activity $(0.26)$, the high value determined from vardenafil intrinsic clearance (0.29), and the lowest value from quinidine intrinsic clearance $(0.044$; using a substrate concentration of $0.1 \mu \mathrm{M}$ ) while the ISEF values for CYP2D6 (derived from bufuralol 1'hydroxylation) was kept constant at 0.14 (Table 5). The resulting risperidone $\mathrm{f}_{\mathrm{m}}$ values ranged from 0.87 to 0.98 for CYP3A4 and from $0.02-0.13$ for CYP2D6, consistent with the sensitivity of this output to the values used for ISEF. Interestingly, CYP2D6 and CYP3A4 both generate the main risperidone metabolite, 9-hydroxyrisperidone, but of opposite stereochemistry (Yasui-Furukori, et al., 2001). Irrespective of the CYP3A4 ISEF used, the CYP3A4 contribution to risperidone clearance is consistently overestimated in comparison to the in vivo CYP2D6 PM vs EM data and ketoconazole DDI data suggesting the clinically derived $f_{m}$ values for these two enzymes is 0.36 for CYP3A4 and 0.63 to 0.88 for CYP2D6. 
For omeprazole (Table 4) the same three ISEF values for CYP3A4 were applied in addition to the CYP2C19 ISEF of 0.50 derived from S-mephenytoin 4'-hydroxylase. The estimates of omeprazole $f_{m}$ values ranged from 0.21 to 0.63 for CYP3A4 and from 0.37 to 0.79 for CYP2C19, reinforcing that $f_{m}$ is sensitive to the values used for ISEF. Clinical estimates for CYP2C19 and CYP3A4 $\mathrm{f}_{\mathrm{m}}$ values are 0.85 and 0.27, respectively, derived from CYP2C19 pharmacogenetic and ketoconazole DDI data. The CYP3A4 ISEF value derived from substrate depletion of quinidine (0.044) yielded the omeprazole CYP3A $f_{m}$ that best predicted the ketoconazole DDI results. Since $f_{m}$ values are relative numbers, the impact or uncertainty of the ISEF for one P450 will impact the overall output, and hence conclusions, for involvement of other P450s to the metabolic clearance of a drug. 


\section{DISCUSSION}

Quantitative estimation of the relative contributions of individual drug metabolizing enzymes to the metabolic clearance of drugs in vitro (a.k.a. reaction phenotyping) is a standard activity in drug research. Data from such experiments are used to understand the potential for inter-patient variability in drug exposure due to phenomena such as being victim to drug-drug interactions and pharmacogenetic differences, among others. One of the common approaches to conducting these investigations is the use of individual cytochrome P450 enzymes. Rates of metabolism of drugs are measured in individually expressed P450 enzymes and these rates are converted to relative contributions using ISEF values. However, it has been our experience, and the experiences of others (Lindmark, et al., 2018; Wang, et al., 2018) that this approach can sometimes fail, or at least offer very different results as compared to the use of human liver microsomes or hepatocytes and P450-selective inhibitors.

In the present investigation, ISEF values for rCYP3A4 were derived from several substrates for purposes of comparing the impact of variability on $\mathrm{f}_{\mathrm{m}}$ prediction. Midazolam metabolism, especially the $1^{\prime}-$ hydroxylase activity, is a commonly employed CYP3A4 marker, and was used in these experiments to calculate three different ISEF values from three different conditions. Enzyme kinetics for 1'hydroxylation yielded an ISEF of 0.26 while measurement of substrate consumption at two substrate concentrations yielded values of $0.36(1.0 \mu \mathrm{M})$ and $0.15(0.1 \mu \mathrm{M})$, representing over a 2 -fold range for a single CYP3A substrate (Table 3). The differences in observed ISEF values derived from substrate consumption at 0.1 and $1.0 \mu \mathrm{M}$ is likely due to the differences in $\mathrm{K}_{\mathrm{M}}$ values between HLM and CYP3A4 being within this range (Table 2), illustrating the importance of using the correct, sub- $\mathrm{K}_{\mathrm{M}}$ substrate concentration. When the derived ISEF values were based on activity of the other CYP3A selective substrates, the values ranged over 8-fold (or 7-fold if the two highest ISEF values generated at higher substrate concentrations are excluded). One possible contributing factor to the observed variability is 
the potential for non-CYP3A involvement in substrate metabolism of liver microsomes. However, the drugs selected in this study were all confirmed to be selective for CYP3A with metabolism shown to be completely inhibited by ketoconazole. Another reason for the observed variability is the potential for CYP3A5 to have meaningful and differential contributions to the metabolism of the drugs selected for this study. It is known that CYP3A5 can catalyze midazolam metabolism (Gibbs, et al., 1999; Tseng, et al., 2014). However, the pooled liver microsomes used in this analysis have been shown to possess very low activity for CYP3A5. CYP3A4 has also been shown to exhibit unusual behavior for an enzyme, with demonstration of inhibitor behavior that is dependent on which substrate is used as the marker activity (Kenworthy, et al., 1999) in addition to non-Michaelis-Menten enzyme kinetics for some substrates (Houston and Galetin, 2004). Also, it has been shown that P450 activities can be influenced by complexation with each other and by the relationship among the enzymes and their partner proteins such as NADPH P450 oxidoreductase and cytochrome b 5 (Reed and Backes, 2012; Yamazaki, et al., 1996). Whether any of these phenomena are behind the observation of different ISEF values for CYP3A4 from different substrates is not known, but the concept of ISEF values is highly dependent on consistent behavior for an enzyme at a molecular level irrespective of the system in which it resides. The data generated in the present work was from rCYP3A4 in a baculovirus Spodoptera frugiperda expression system however the findings are not unique to this system since similar observations by others used rCYP3A4 from different sources (Lindmark, et al., 2018; Wang, et al., 2018; Siu, et al., 2017).

Obtaining different ISEF values using different marker substrates is highly detrimental to the approach of using data from individually expressed P450 enzymes for estimates of $f_{m}$ values. This was illustrated in the examples of risperidone and omeprazole wherein it is known that CYP3A4 plays a partial role in drug clearance (Bottiger, et al., 1997; Mahatthanatrakul, et al., 2012). Omeprazole has been shown clinically to be mostly metabolized by CYP2C19, through demonstrated differences in exposure between 
CYP2C19 extensive and poor metabolizers, with only a minor contribution from CYP3A4 (Bottiger, et al., 1997). However, estimating $f_{m}$ for CYP3A4 for omeprazole metabolism by using the higher ISEF values derived from 1'-hydroxymidazolam formation $\mathrm{CL}_{\text {int }}$ and vardenafil depletion $\mathrm{CL}_{\text {int }}$, suggests that $\mathrm{CYP3A4}$ is the major enzyme involved in its clearance (Table 5) with respective $f_{m}$ values of 0.60 and 0.63 ; and since $f_{m}$ values are relative, it then also suggests that CYP2C19 is only a minor contributing enzyme $\left(f_{m}<\right.$ 0.40). Use of the lowest ISEF value, 0.044 derived from quinidine intrinsic clearance, yields $f_{m}$ values for omeprazole metabolism by CYP3A4 more closely reflecting the in vivo situation (0.21 vs 0.27 , respectively). Prior to having in vivo data for a new drug, it would be difficult to know which ISEF value to use for $f_{m}$ estimation. For risperidone, the case is more concerning. Risperidone is known to be primarily cleared by CYP2D6, as shown by comparing CYP2D6 extensive and poor metabolizers (Gasso, et al., 2014; Cabaleiro, et al., 2014). However, the use of metabolism data from recombinant CYP3A4 and CYP2D6 and the respective ISEF values suggest that CYP3A4 is the dominant enzyme in risperidone clearance $\left(f_{m}\right.$ of $\left.0.87-0.98\right)$ regardless of which CYP3A4 ISEF value is employed. When used prospectively, this leads to a complete misassignment of the importance of CYP2D6 in risperidone clearance.

Overall these findings, along with the findings of others (Lindmark, et al., 2018; Wang, et al., 2018; Siu, et al., 2017), cast doubt on the quantitative reliability of the approach of using metabolism data from recombinant hetereologously expressed P450 enzymes. This is because among all the P450 enzymes, CYP3A4 is the most frequent enzyme involved in the metabolism of drugs, but ISEF values calculated for CYP3A4 vary broadly with the substrate used. Successful employment of the ISEF approach is dependent on all marker substrates used to calculate ISEF values to be metabolized similarly in human liver microsomes and recombinant systems. Some experimental variability from substrate to substrate can be expected, however the 8-fold difference observed for CYP3A4 is too high to be useful. For a new 
investigational compound that is metabolized by CYP3A4, it cannot be known ahead of time which of the model CYP3A4 substrates used in generating ISEF values would be most comparable, and thus which ISEF value to use when scaling for fraction metabolized. This phenomenon reduces the effectiveness of the approach of using metabolism data from rCYP3A4 with ISEF values for the prediction of $f_{m}$ values in vivo. While heterologously expressed P450 enzymes can be useful in identifying which enzymes have the potential to be involved in metabolism, the quantitative assignment of individual enzymes will require confirmation using other approaches, such as the use of P450 selective inhibitors in human liver microsomes. Research into this is ongoing and will be reported in due course.

\title{
ACKNOWLEDGEMENTS
}

Support of this research endeavor from Drs. Larry Tremaine and Theunis Goosen is gratefully acknowledged.

\author{
AUTHOR CONTRIBUTIONS \\ Participated in Research Design: Dantonio, Doran, Obach \\ Conducted Experiments: Dantonio, Doran, Obach \\ Performed Data Analysis: Dantonio, Doran, Obach \\ Wrote or Contributed to Writing the Manuscript: Dantonio, Doran, Obach
}




\section{REFERENCES}

Abelö A, Andersson TB, Antonsson M, Naudot AK, Skånberg I, Weidolf L. (2000) Stereoselective metabolism of omeprazole by human cytochrome P450 enzymes. Drug Metab Dispos. 28:96672.

Austin RP, Barton P, Cockroft SL, Wenlock MC, Riley RJ. (2002) The influence of nonspecific microsomal binding on apparent intrinsic clearance, and its prediction from physicochemical properties. Drug Metab Dispos. 30:1497-503.

Bondolfi G, Eap CB, Bertschy G, Zullino D, Vermeulen A, Baumann P. (2002) The effect of fluoxetine on the pharmacokinetics and safety of risperidone in psychotic patients. Pharmacopsychiatry. 35:50-6.

Böttiger Y, Tybring G, Götharson E, Bertilsson L. (1997) Inhibition of the sulfoxidation of omeprazole by ketoconazole in poor and extensive metabolizers of S-mephenytoin. Clin Pharmacol Ther. 62:384-91.

Cabaleiro T, Ochoa D, López-Rodríguez R, Román M, Novalbos J, Ayuso C, Abad-Santos F. (2014) Effect of polymorphisms on the pharmacokinetics, pharmacodynamics, and safety of risperidone in healthy volunteers. Hum Psychopharmacol. 29:459-69.

Cerny M, (2016) Prevalence of non-cytochrome P450-mediated metabolism in Food and Drug Administration-approved oral and intravenous drugs: 2006-2015. Drug Metab Dispo 44:12461252.

Chen Y, Liu L, Nguyen K, Fretland AJ (2011). Utility of intersystem extrapolation factors in early reaction phenotyping and the quantitative extrapolation of human liver microsomal intrinsic clearance using recombinant cytochromes P450. Drug Metab Dispos 39: 373-382.

Dai Dai Y, Hebert MF, Isoherranen N, Davis CL, Marsh C, Shen DD, Thummel KE. (2006) Effect of CYP3A5 polymorphism on tacrolimus metabolic clearance in vitro. Drug Metab Dispos 34:836-847. 
Dennison JB, Kulanthaivel P, Barbuch RJ, Renbarger JL, Ehlhardt WJ, Hall SD. (2006) Selective metabolism of vincristine in vitro by CYP3A5. Drug Metab Dispos 34:1317-1327.

Ekroos M and Sjögren T. (2006) Structural basis for ligand promiscuity in cytochrome P450 3A4. Proc Natl Acad Sci U S A. 103:13682-7.

Gassó P, Mas S, Papagianni K, Ferrando E, de Bobadilla RF, Arnaiz JA, Bioque M, Bernardo M, Lafuente A. (2014) Effect of CYP2D6 on risperidone pharmacokinetics and extrapyramidal symptoms in healthy volunteers: results from a pharmacogenetic clinical trial. Pharmacogenomics. 15:17-28.

Gibbs MA, Thummel KE, Shen DD, Kunze KL. (1999) Inhibition of cytochrome P-450 3A (CYP3A) in human intestinal and liver microsomes: comparison of Ki values and impact of CYP3A5 expression. Drug Metab Dispos. 27:180-7.

Greenblatt DJ, Peters DE, Oleson LE, Harmatz JS, MacNab MW, Berkowitz N, Zinny MA, Court MH. (2009) Inhibition of oral midazolam clearance by boosting doses of ritonavir, and by 4,4-dimethylbenziso-(2H)-selenazine (ALT-2074), an experimental catalytic mimic of glutathione oxidase. $\mathrm{Br} \mathrm{J}$ Clin Pharmacol. 68:920-7.

Guengrich FP, (2008) Cytochrome P450 and chemical toxicology. Chem Res Toxicol 21:70-83.

Heinig R, Adelmann HG, Ahr G. (1999) The effect of ketoconazole on the pharmacokinetics, pharmacodynamics and safety of nisoldipine. Eur J Clin Pharmacol. 55:57-60.

Houston JB. (1994) Utility of in vitro drug metabolism data in predicting in vivo metabolic clearance. Biochem Pharmacol. 47:1469-1479.

Houston JB and Glaetin A, (2005) Modelling atypical CYP3A4 kinetics: principles and pragmatism. Arch Biochem Biophyics. 433:351-360.

Jalava KM, Olkkola KT, Neuvonen PJ. (1997) Itraconazole greatly increases plasma concentrations and effects of felodipine. Clin Pharmacol Ther. 61:410-5. 
Kapelyukh Y, Paine MJ, Maréchal JD, Sutcliffe MJ, Wolf CR, Roberts GC. (2008) Multiple substrate binding by cytochrome P450 3A4: estimation of the number of bound substrate molecules. Drug Metab Dispos. 36:2136-44.

Kenworthy KE, Bloomer JC, Clarke SE, Houston JB. (1999) CYP3A4 drug interactions: correlation of 10 in vitro probe substrates. Br J Clin Pharmacol. 48:716-27.

Kaukonen KM, Olkkola KT, Neuvonen PJ. (1997) Itraconazole increases plasma concentrations of quinidine. Clin Pharmacol Ther. 62:510-7.

Lee JE, van Heeswijk R, Alves K, Smith F, Garg V. (2011) Effect of the hepatitis C virus protease inhibitor telaprevir on the pharmacokinetics of amlodipine and atorvastatin. Antimicrob Agents Chemother. 55:4569-74.

Lindmark B, Lundahl A, Kanebratt KP, Andersson TB, Isin EM. (2018) Human hepatocytes and cytochrome P450-selective inhibitors predict variability in human drug exposure more accurately than human recombinant P450s. Br J Pharmacol. 175:2116-2129.

Lu AYH, Wang RW, and Lin JH (2003) Cytochrome P450 In Vitro Phenotyping: A re-evaluation of Approaches Used for P450 Isoform Identification. Drug Metab Dispo 31:345-350.

Mahatthanatrakul W, Sriwiriyajan S, Ridtitid W, Boonleang J, Wongnawa M, Rujimamahasan N, Pipatrattanaseree W. (2012) Effect of cytochrome P450 3A4 inhibitor ketoconazole on risperidone pharmacokinetics in healthy volunteers. J Clin Pharm Ther. 37:221-5.

Muirhead GJ, Wulff MB, Fielding A, Kleinermans D, Buss N. (2000) Pharmacokinetic interactions between sildenafil and saquinavir/ritonavir. Br J Clin Pharmacol. 50:99-107.

Niwa T, Murayama N, Emoto C, Yamazaki H. (2008) Comparison of kinetic parameters for drug oxidation rates and substrate inhibition potential mediated by cytochrome P450 3A4 and 3A5. Curr Drug Metab 9:20-33. 
Reed JR and Backes WL. (2012) Formation of P450 - P450 complexes and their effect on P450 function. Pharmacol Ther. 133:299-310.

Rodrigues AD. (1999) Integrated cytochrome P450 reaction phenotyping: attempting to bridge the gap between cDNA-expressed cytochromes P450 and native human liver microsomes. Biochem Pharmacol. 57:465-80.

Siu YA and Lai GW. (2017) Impact of probe substrate selection on cytrochrome P450 reaction phenotyping using the relative activity factor. Drug Metab Dispo. 45:183-189.

Spina E, Avenoso A, Facciolà G, Scordo MG, Ancione M, Madia A. (2001) Plasma concentrations of risperidone and 9-hydroxyrisperidone during combined treatment with paroxetine. Ther Drug Monit. 23:223-7.

Tseng E, Walsky RL, Luzietti RA Jr, Harris JJ, Kosa RE, Goosen TC, Zientek MA, Obach RS. (2014) Relative contributions of cytochrome CYP3A4 versus CYP3A5 for CYP3A-cleared drugs assessed in vitro using a CYP3A4-selective inactivator (CYP3cide). Drug Metab Dispos. 42:1163-73.

Varhe A, Olkkola KT, Neuvonen PJ. (1994) Oral triazolam is potentially hazardous to patients receiving systemic antimycotics ketoconazole or itraconazole. Clin Pharmacol Ther. 56:601-7.

Wang S, Tang X, Yant T, Xu J, Zhang J, Liu X, Liu L. (2018) Predicted contributions of cytochrome P450s to drug metabolism in human liver microsomes using relative activity factor were dependent on probes. Xenobiotica, 49: 161-168.

Yamazaki H, Johnson WW, Ueng YF, Shimada T, Guengerich FP. (1996) Lack of electron transfer from cytochrome b5 in stimulation of catalytic activities of cytochrome P450 3A4. Characterization of a reconstituted cytochrome $\mathrm{P} 450$ 3A4/NADPH-cytochrome $\mathrm{P} 450$ reductase system and studies with apo-cytochrome b5. J Biol Chem. 271:27438-44.

Yamazaki H, Inoue K, Shaw PM, Checovich WJ, Guengerich FP, Shimada T. (1997) Different contributions of cytochrome P450 2C19 and 3A4 in the oxidation of omeprazole by human liver microsomes: 
effects of contents of these two forms in individual human samples. J Pharmacol Exp Ther. 283:434-42.

Yasui-Furukori N, Hidestrand M, Spina E, Facciolá G, Scordo MG, Tybring G. (2001) Different enantioselective 9-hydroxylation of risperidone by the two human CYP2D6 and CYP3A4 enzymes. Drug Metab Dispos. 29:1263-8.

Yu J, Ritchie TK, Mulgaonkar A, and Ragueneau-Majlessi I (2014) Drug disposition and drug-drug interaction data in 2013 FDA new drug application: a systemic review. Drug Metab Dispo 42:1991-2001.

Zhang H, Davis CD, Sinz MW, and Rodrigues AD (2007) Cytochrome P450 reaction-phenotyping: an industrial perspective. Expert Opin Drug Metab Toxic 3:667-787.

Zhu Y, Wang F, Li Q, Zhu M, Du A, Tang W, Chen W. (2014) Amlodipine metabolism in human liver microsomes and roles of CYP3A4/5 in the dihydropyridine dehydrogenation. Drug Metab Dispo 42(2):245-259.

Zientek MA, Youdim K, (2015) Reaction Phenotyping: Advances in the experimental strategies used to characterize the contribution of drug-metabolizing enzymes. Drug Metab Dispo 43:163-181.

This paper received no external funding. No author has an actual or perceived conflict of interest with the contents of this article 


\section{FIGURE LEGENDS}

FIGURE 1. Enzyme kinetics of midazolam 1'-hydroxylation in pooled human liver microsomes and recombinant heterologously expressed CYP3A4. Panels A and B represent two separate experiments conducted in human liver microsomes and panels $C$ and $D$ represent two separate experiments conducted in rCYP3A4. Error bars represent standard deviation and dotted lines represent 95\% confidence intervals of the resulting curves.

FIGURE 2. Depletion of CYP3A4 substrates $(1 \mu \mathrm{M})$ incubated at $0.01,0.1$, or $1 \mathrm{mg} / \mathrm{mL}$ human liver microsomes (blue squares) or 1, 10, or $100 \mathrm{pmol} / \mathrm{mL}$ rCYP3A4 (red circles). Varying levels of protein were used to best capture first order kinetics of substrate decline. Compounds repeated at lower substrate $(0.1 \mu \mathrm{M})$ are shown as open symbols.

Figure 3. The distribution of ISEF values, calculated either by substrate depletion or 1'hydroxymidazolam metabolite formation (blue triangle). Black symbols represent the compounds run at $1 \mu \mathrm{M}$ and red symbols represent the three compounds repeated at $0.1 \mu \mathrm{M}$ (quinidine, nisoldipine, and midazolam) to ensure substrate concentration was sufficiently below $\mathrm{K}_{\mathrm{M}}$.

FIGURE 4. Depletion of CYP3A4 substrates $(1 \mu \mathrm{M})$ incubated at $0.01,0.1$ or $1 \mathrm{mg} / \mathrm{mL}$ human liver microsomes in in the presence of CYP3A4/5 competitive inhibitor ketoconazole $(1 \mu \mathrm{M})$ or CYP3A4 inactivator CYP3cide $(1 \mu \mathrm{M})$ compared with solvent control. Error bars represent standard deviation. Varying levels of protein were chosen to best capture first order kinetics of substrate decline. For amlodipine, the impact of CYP3A4 was difficult to discern due to a slow rate substrate depletion. The CYP3A4 $f_{m}$, of dehydroamlodipine formation was determined to be 0.97 in pooled human hepatocytes in the presence and absence of $25 \mu \mathrm{M}$ troleadomycin.

FIGURE 5. Metabolism of risperidone and omeprazole by recombinant heterologously expressed cytochrome P450 enzymes. Panel A: Risperidone depletion in rCYP3A4 (circles) and rCYP2D6 (squares). Panel B: Omeprazole depletion in rCYP3A4 (circles) and rCYP2C19 (squares). 
TABLE 1. Summary of DDI for nine of the drugs selected for this analysis. The estimates for $f_{m}$ represent lower limits with an assumption that the perpetrator drug causes complete inhibition of CYP3A in vivo.

\begin{tabular}{|c|c|c|c|c|}
\hline Drug & $\begin{array}{c}\text { Clinical DDI } \\
\text { (Fold-Increase } \\
\text { in Exposure) }\end{array}$ & DDI Perpetrator & In vivo $\mathrm{f}_{\mathrm{m}}$ & Reference for DDI Study \\
\hline Vardenafil & 49.1 & ritonavir & 0.98 & LEVITRA Package Insert \\
\hline Midazolam & 26.4 & ritonavir & 0.96 & Greenblatt, et al., 2009 \\
\hline Nisoldipine & 25.3 & ketoconazole & 0.96 & Heinig, et al., 1999 \\
\hline Triazolam & 22.3 & ketoconazole & 0.96 & Varhe, et al., 1994 \\
\hline Sildenafil & 9.9 & ritonavir & 0.90 & Jalava, et al., 1997 \\
\hline Felodipine & 6.3 & itraconazole & 0.84 & RELPAX Package Insert \\
\hline Eletriptan & 5.9 & ketoconazole & 0.83 & Lee, et al., 2011 \\
\hline Amlodipine & 3.0 & telapravir & 0.67 & Kaukonen, et al., 1997 \\
\hline Quinidine & 2.4 & itraconazole & 0.58 & \\
\hline
\end{tabular}


TABLE 2. Enzyme kinetic parameters for midazolam 1'-hydroxylation in pooled human liver microsomes and heterolo

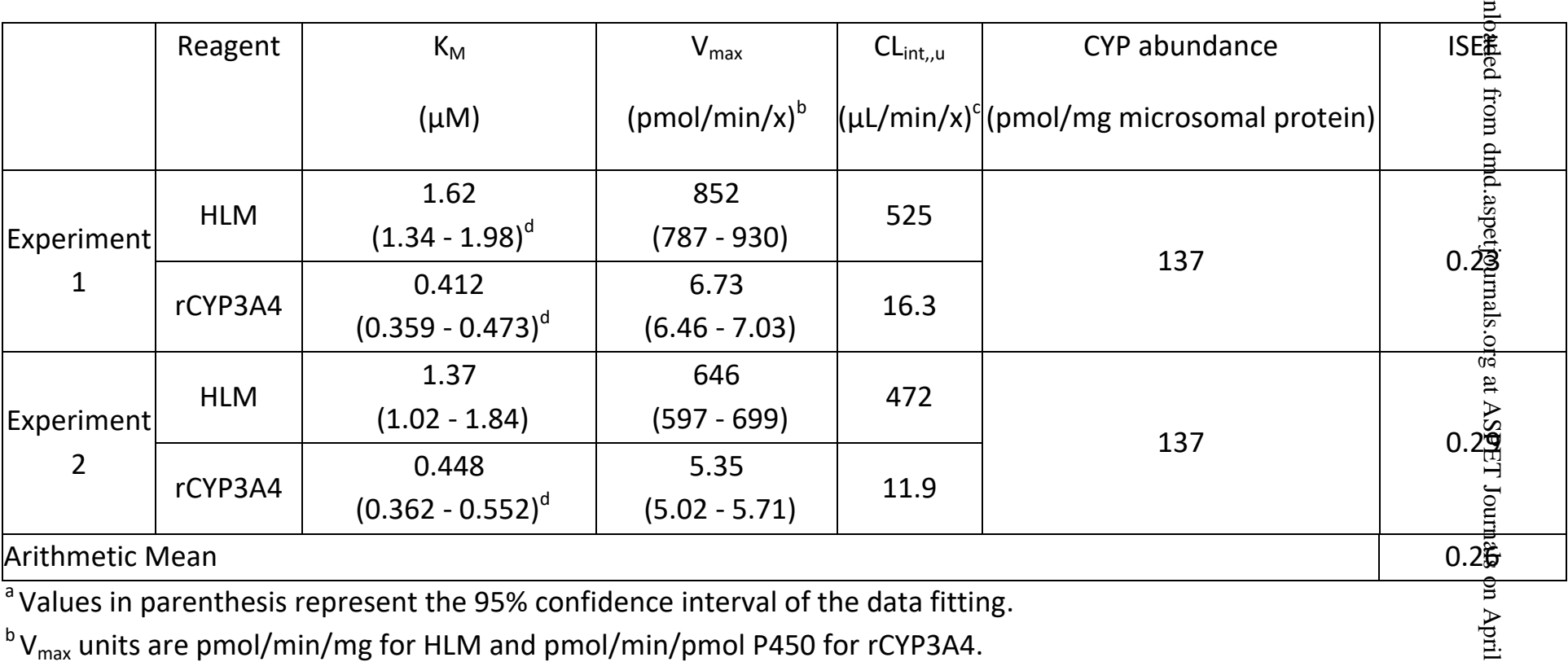

$\mathrm{V}_{\text {max }}$ units are $\mathrm{pmol} / \mathrm{min} / \mathrm{mg}$ for HLM and pmol/min/pmol P450 for rCYP3A4.

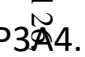

${ }^{\mathrm{d}}$ Data fit to substrate inhibition model, resulting $\mathrm{K}_{\mathrm{i}}$ values were $>100 \mu \mathrm{M}$ ( 3 times the highest substrate concentration $\mathbb{N}_{\mathrm{N}}^{\mathrm{t}}$. 
TABLE 3. Intrinsic clearance and calculated CYP3A4 ISEF values for ten substrates.

\begin{tabular}{|c|c|c|c|}
\hline \multirow[b]{2}{*}{ Compound } & \multicolumn{2}{|c|}{$\overline{\mathrm{CL}_{\text {int, }, \mathrm{u}}}$} & \multirow{2}{*}{ ISEF } \\
\hline & CYP3A4 & HLM & \\
\hline Midazolam $(1.0 \mu \mathrm{M})$ & 8.50 & 417 & 0.36 \\
\hline Nisoldipine $(1.0 \mu \mathrm{M})$ & 91.9 & 4129 & 0.32 \\
\hline Vardenafil & 9.75 & 376 & 0.29 \\
\hline Midazolam (1'-hydroxymidazolam formation) & 14.1 & 498 & 0.26 \\
\hline Triazolam & 1.47 & 37.1 & 0.19 \\
\hline Sildenafil & 9.89 & 239 & 0.18 \\
\hline Felodipine & 97.9 & 2275 & 0.17 \\
\hline Midazolam $(0.1 \mu \mathrm{M})$ & 32.8 & 690 & 0.15 \\
\hline Nisoldipine $(0.1 \mu \mathrm{M})$ & 383 & 7093 & 0.14 \\
\hline Vincristine & 0.659 & 12.8 & 0.14 \\
\hline Amlodipine & 8.97 & 95.3 & 0.077 \\
\hline Quinidine $(1.0 \mu \mathrm{M})$ & 2.52 & 20.1 & 0.058 \\
\hline Eletriptan & 4.29 & 29.2 & 0.050 \\
\hline Quinidine $(0.1 \mu \mathrm{M})$ & 3.30 & 19.8 & 0.044 \\
\hline
\end{tabular}

Units are $\mu \mathrm{L} / \mathrm{min} / \mathrm{pmol}$ P450 for rCYP3A4 and $\mu \mathrm{L} / \mathrm{min} / \mathrm{mg}$ protein for HLM. 
TABLE 4. Use of CYP3A4 ISEF from Three Substrates in the Estimation of $f_{m}$ Values for Omeprazole.

\begin{tabular}{|c|c|c|c|c|c|c|c|}
\hline \multirow[b]{2}{*}{ rCYP } & \multicolumn{3}{|c|}{ ISEF Parameters } & \multicolumn{2}{|c|}{$\mathrm{CL}_{\text {int }}$} & \multicolumn{2}{|c|}{$f_{m}$} \\
\hline & Reaction & $\begin{array}{l}\text { ISEF } \\
\text { Value }\end{array}$ & $\begin{array}{c}\text { CYP } \\
\text { Abundance }\end{array}$ & $\begin{array}{c}\text { rCYP } \mathrm{CL}_{\text {int,u }} \\
(\mu \mathrm{L} / \mathrm{min} / \mathrm{pmol} \mathrm{P} 450)\end{array}$ & $\begin{array}{c}\text { ISEF-derived } \\
\mathrm{HLM} \mathrm{CL}_{\text {int,sc,u }}(\mathrm{mL} / \mathrm{min} / \mathrm{kg}\end{array}$ & $\begin{array}{c}\text { In Vitro } \\
f_{m}\end{array}$ & $\begin{array}{c}\text { In Vivo } \\
f_{m}\end{array}$ \\
\hline \multirow{3}{*}{ rCYP3A4 } & $\begin{array}{c}\text { 1'-Hydroxymidazolam } \\
\text { Formation }\end{array}$ & 0.26 & \multirow{3}{*}{137} & \multirow{3}{*}{2.35} & 75.4 & 0.60 & \multirow{3}{*}{$0.27^{b}$} \\
\hline & Vardenafil Depletion & 0.29 & & & 84.1 & 0.63 & \\
\hline & Quinidine Depletion & 0.044 & & & 12.8 & 0.21 & \\
\hline rCYP2C19 & $\begin{array}{c}\text { (S)-Mephenytoin 4'- } \\
\text { Hydroxylation }\end{array}$ & $0.50^{c}$ & 14 & 7.84 & 49.4 & $0.37-0.79$ & $0.85^{d}$ \\
\hline
\end{tabular}

${ }^{a}$ Binding values were scaled using equation described in Austin et al (2002), from values generated via equilibrium diådysis. Measured $\mathrm{f}_{\mathrm{u} \text {,mic }}$ for omeprazole was 0.90 at $0.71 \mathrm{mg} / \mathrm{mL}$, which scaled to $\mathrm{f}_{\mathrm{u}, \mathrm{inc}}$ of $0.98,0.99$, and 0.87 for rCYP3A4, rCYP2C19, and HLM incutbations, respectively.

${ }^{b}$ Calculated from clinical data reported in Bottiger, et al., 1997.

$$
\text { : }
$$

${ }^{C}$ CYP2C19 ISEF determined from mephenytoin 4'-hydroxylase activity (internal data on file, Pfizer, Inc.) This ISEF has B̈ Been used successfully for other CYP2C19 cleared drugs.

${ }^{d}$ Median $f_{m}$ value calculated from fifty clinical studies in which omeprazole was dosed to CYP2C19 extensive and poor metabolizers, obtained from the University of Washington Drug Interaction Database. 
TABLE 5. Use of CYP3A4 ISEF from Three Substrates in the Estimation of $\mathrm{f}_{\mathrm{m}}$ Values for Risperidone.

\begin{tabular}{|c|c|c|c|c|c|c|c|}
\hline \multirow{2}{*}{ rCYP } & \multicolumn{3}{|c|}{ ISEF Parameters } & \multicolumn{2}{|c|}{$\mathrm{CL}_{\text {int }}$} & \multicolumn{2}{|c|}{$f_{m}$} \\
\hline & Reaction & $\begin{array}{l}\text { ISEF } \\
\text { Value }\end{array}$ & $\begin{array}{c}\text { CYP } \\
\text { Abundance }\end{array}$ & $\begin{array}{c}\text { rCYP CL } \text { int,u } \\
(\mu \mathrm{L} / \mathrm{min} / \mathrm{pmol} \mathrm{P} 450)\end{array}$ & $\begin{array}{l}\text { ISEF-derived HLM CL } \mathrm{CL}_{\text {int }, \mathrm{sc}, \mathrm{u}} \\
(\mathrm{mL} / \mathrm{min} / \mathrm{kg})^{\mathrm{d}}\end{array}$ & $\begin{array}{l}\text { In Vitro } \\
f_{m}\end{array}$ & $\begin{array}{l}\text { In Vivo } \\
\mathrm{f}_{\mathrm{m}}\end{array}$ \\
\hline \multirow{3}{*}{ rCYP3A4 } & $\begin{array}{c}\text { 1'-Hydroxymidazolam } \\
\text { Formation }\end{array}$ & 0.26 & \multirow{3}{*}{137} & \multirow{3}{*}{1.62} & 51.9 & 0.98 & \multirow{3}{*}{$0.36^{b}$} \\
\hline & Vardenafil Depletion & 0.29 & & & 57.9 & 0.98 & \\
\hline & Quinidine Depletion & 0.044 & & & 8.79 & 0.87 & \\
\hline rCYP2D6 & $\begin{array}{l}\text { Bufuralol 1'- } \\
\text { Hydroxylation }\end{array}$ & $0.14^{\mathrm{a}}$ & 8 & 1.31 & 1.32 & $0.02-0.13$ & $0.63-0.88^{c}$ \\
\hline
\end{tabular}

${ }^{a}$ CYP2D6 ISEF determined from bufuralol 1'-hydroxylase activity (internal data on file, Pfizer, Inc.) This ISEF has been $\tilde{u}_{n}$ sed successfully for other CYP2D6 cleared drugs.

${ }^{\mathrm{b}}$ Mahatthanatrakul, et al., 2012.

'Spina, et al., 2001; Gasso, et al., 2014; Cabaliero, et al., 2014; Bondolfi, et al., 2001.

Binding values were scaled using equation described in Austin et al (2002), from values generated via equilibrium diă risperidone in human liver microsomes was 0.860 at $0.71 \mathrm{mg} / \mathrm{mL}$, which scaled to $\mathrm{f}_{\mathrm{u} \text {,inc }}$ of $0.57,0.95$, and 0.60 for $\mathrm{rCYP} 3 \mathrm{~S}$, $\mathrm{rCYP} 2 \mathrm{D6}$, and human liver microsome incubations, respectively. 
Figure 1

A

B
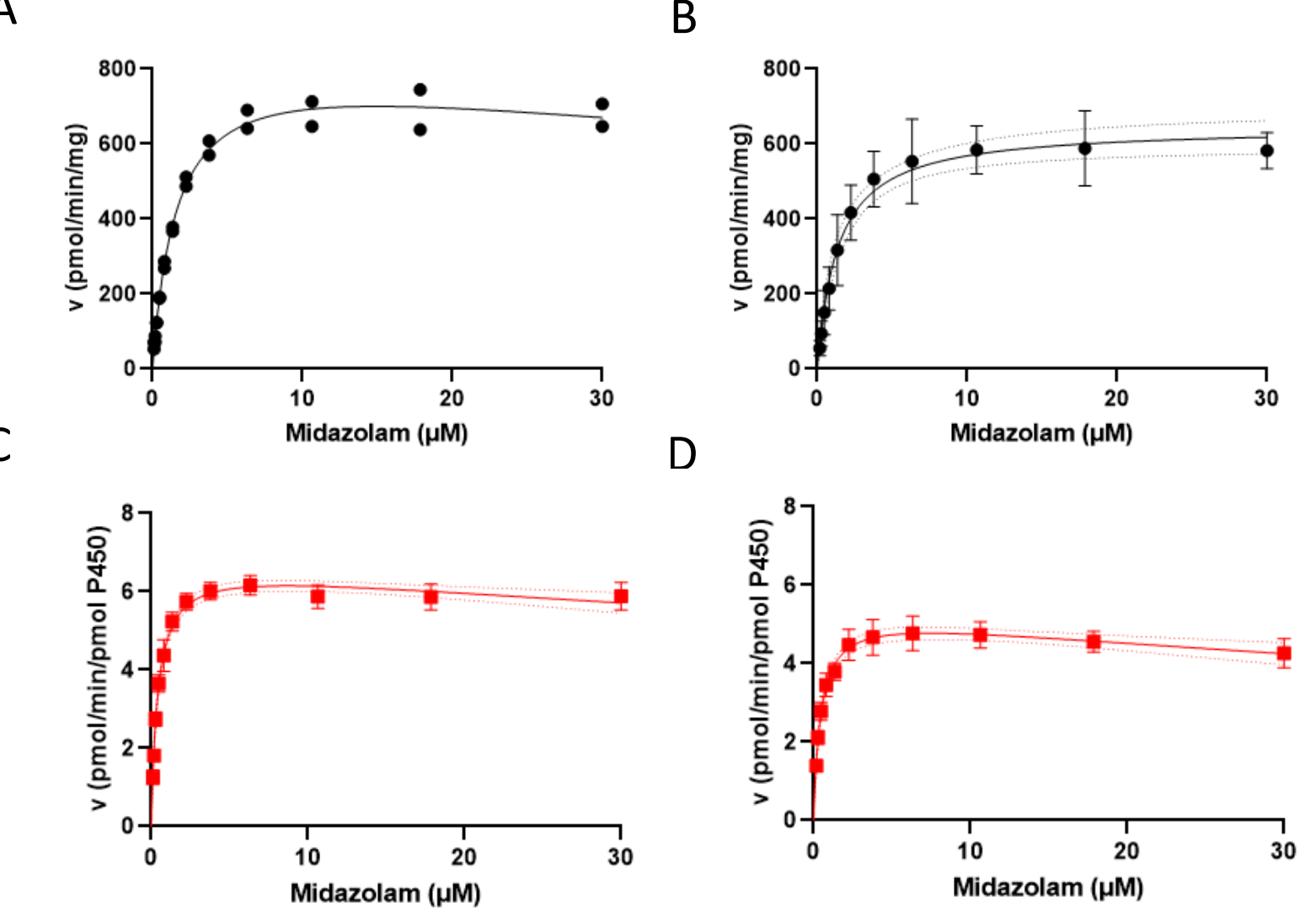

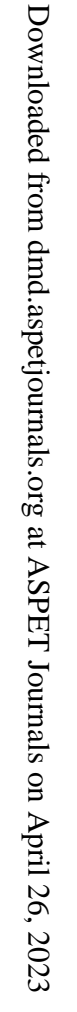



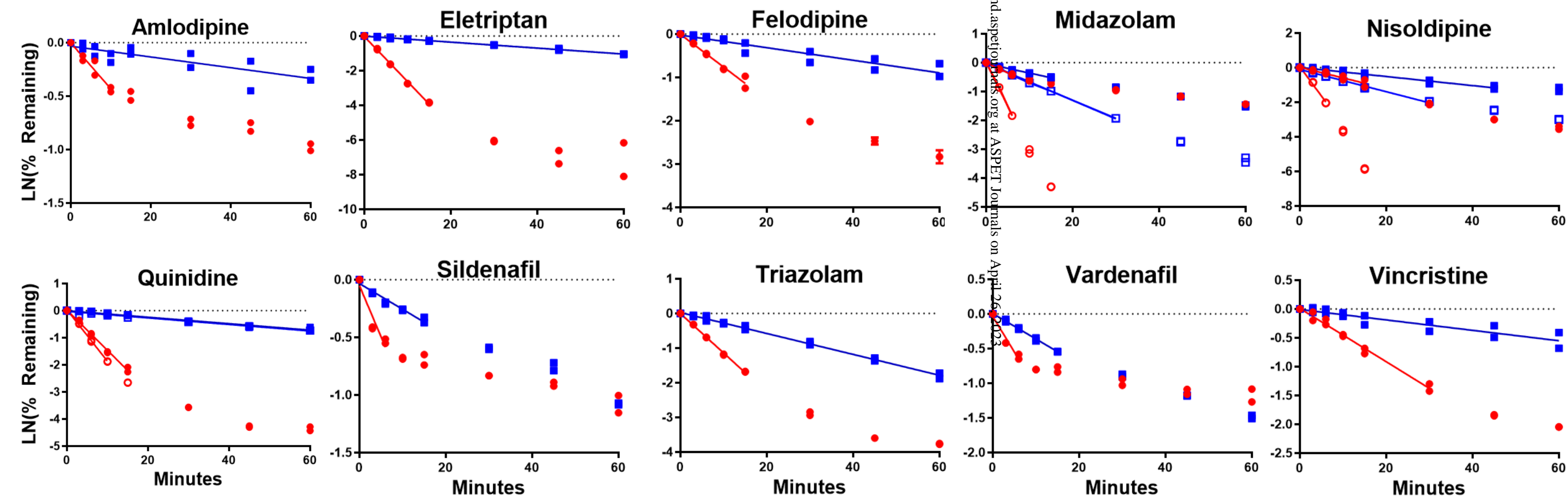


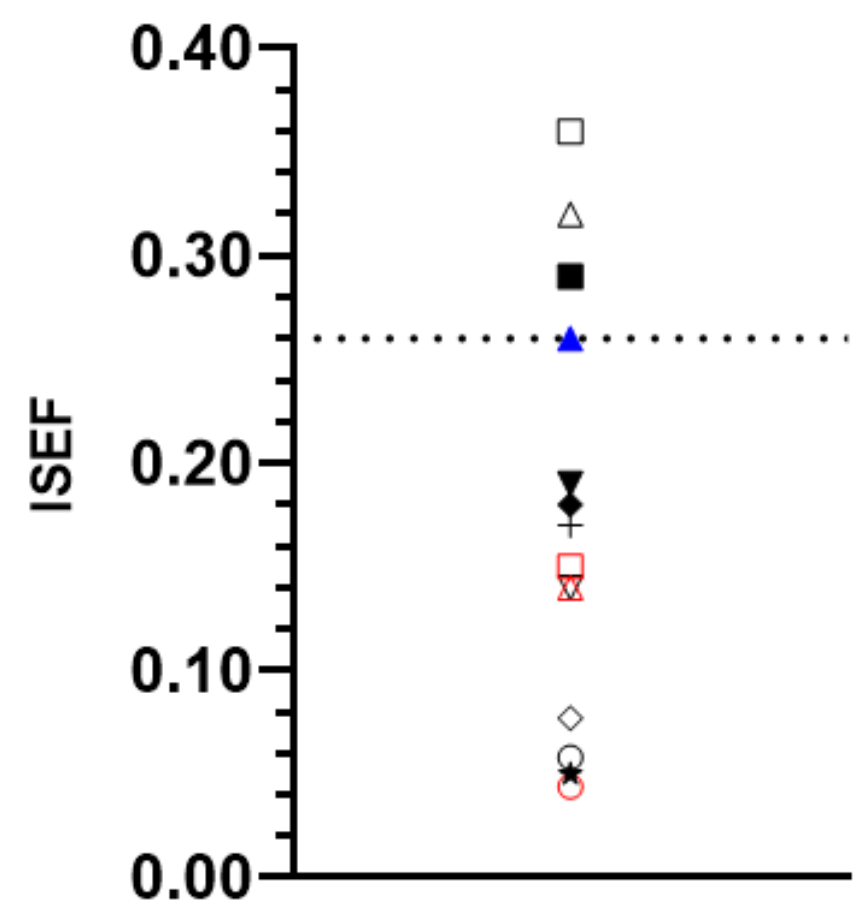

$\square$ Midazolam

$\triangle$ Nisoldipine

- Vardenafil

^ Midazolam (1'-H-MDZ ISEF)

v Triazolam

- Sildenafil

+ Felodipine

$\square$ Midazolam (0.1

$\triangle$ Nisoldipine $(0.1 / f \mu M)$

$\nabla$ Vincristine

$\diamond$ Amlodipine

- Quinidine

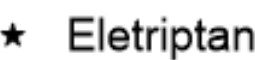

○ Quinidine $(0.1 \mu \mathrm{M})$

Figure 3 

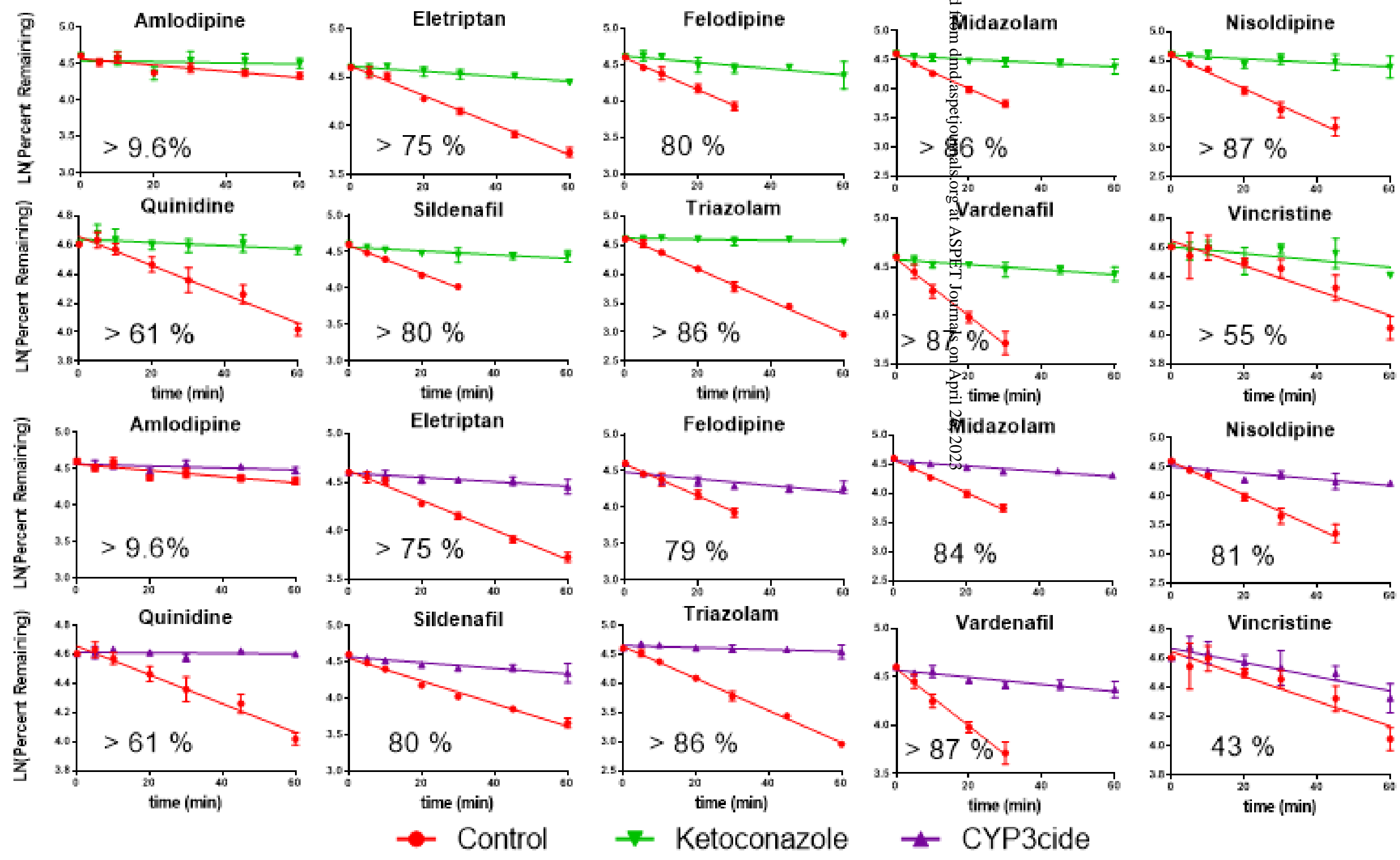

\section{Figure 4}




\section{B}

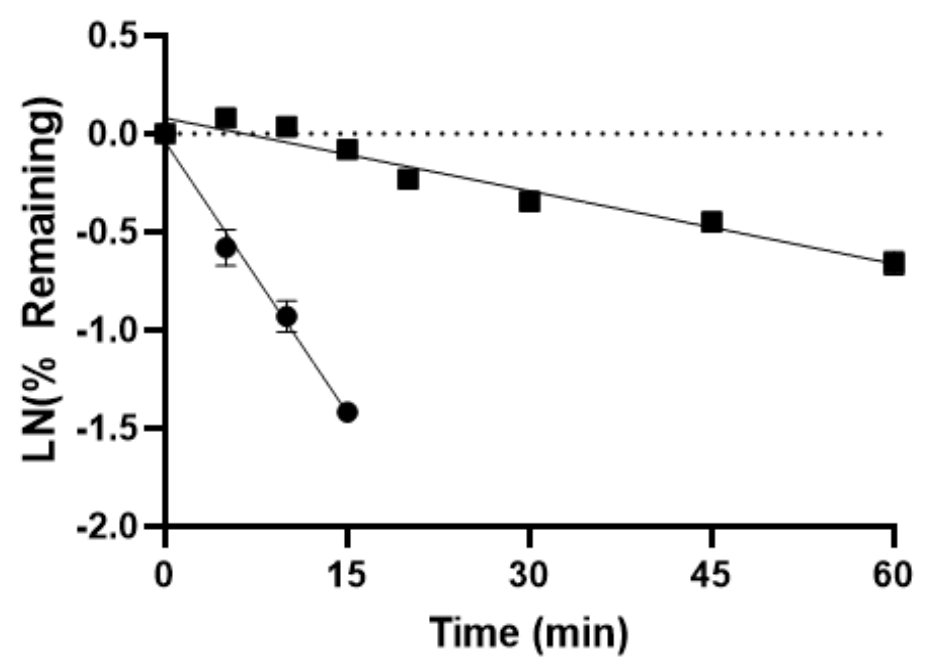

- $10 \mathrm{pmol} / \mathrm{mL}$ rCYP2D6

-- $100 \mathrm{pmol} / \mathrm{mL}$ rCYP3A4
- $10 \mathrm{pmol} / \mathrm{mL}$ rCYP2C19

- $10 \mathrm{pmol} / \mathrm{mL}$ rCYP3A4

Figure 5 